\title{
28 Research Suare \\ Cross-sectional study on awareness and knowledge of COVID-19 among senior pharmacy students.
}

\section{Marwa Samir Hamza ( $\square$ marwa.hamza@bue.edu.eg )}

Clinical Pharmacy Practice Department, Faculty of Pharmacy, The British University in Egypt

\section{Osama Ahmed Badary}

Clinical Pharmacy Practice Department, Faculty of Pharmacy, The British University in Egypt

\section{Mohamed Mohey Elmazar}

Pharmacology and Biochemistry Department, Faculty of Pharmacy, The British University in Egypt

\section{Research Article}

Keywords: COVID-2019; knowledge; attitude; practice; Egypt

Posted Date: June 5th, 2020

DOI: https://doi.org/10.21203/rs.3.rs-33352/v1

License: (c) (1) This work is licensed under a Creative Commons Attribution 4.0 International License.

Read Full License

Version of Record: A version of this preprint was published at Journal of Community Health on June 15th, 2020. See the published version at https://doi.org/10.1007/s10900-020-00859-z. 


\section{Abstract}

Extraordinary actions have been implemented in an effort to control the rapid spread of the ongoing COVID-19 epidemic in Egypt. People's adherence to control measures is influenced by their knowledge, attitudes and practices towards the disease. Therefore, in the present study we assessed pharmacy senior students' knowledge, attitudes and practices towards the COVID-19 pandemic. An online questionnaire was created and it consisted of 12 questions testing their knowledge about COVID19 nclinical characteristics, transmission routes and prevention and control steps. Among senior pharmacy students $(n=238), 70 \%$ were females and $63 \%$ were living in greater Cairo. Their main source of information included social media (70\%), published articles (48\%) and television (48\%). The overall correct knowledge score was $83 \%$. Most of the students displayed a good COVID-19 knowledge level (72.5\% of the students). The students were least informed when trying to answer questions about hypercoagulation, as a major cause for death in patients with severe COVID-19, and about the timings on the necessity to wear masks practice. Assessment of students' attitudes and practices towards COVID-19 reflected that $87 \%$ of them were confident that health care teams and scientists could win the fight against the virus. In addition, $72 \%$ of students agreed that COVID-19 will be controlled successfully. The greater the students' knowledge, the more confident they felt that COVID-19 will be controlled successfully (OR $=2.2,95 \%$ confidence interval [CI]: 1.03-4.72). Good behavioral practice towards COVID-19 control was confirmed when $87 \%$ of students answered that they didn't go out to any crowded place. Females were 3.6 times (95\% confidence interval [CI]: 1.03-3.11) more likely to avoid going out than males. Bad behavioral practice became evident when approximately $50 \%$ of students admitted that they did not wear masks when they left their house. Therefore, more efforts should be taken to protect future pharmacists from this pandemic.

\section{Introduction}

An epidemic, triggered by the new coronavirus SARS-CoV-2, hasrecently become the focus of the scientific community attention[1]. COVID-19 represents the illnessgenerated by this virus. Its clinical presentation ranges frombeing an asymptomatic infection to developing into a severe diseasewith high mortality rate [2]. At the timeof writing (May 16, 2020), over 4,425,485 COVID-19 cases and302,059 death have been registered worldwide [3]. In particular, in Egypt, there are 11,228positive individuals and 592 death cases [4]. Now, COVID-19 has been classified as a pandemicby the World Health Organization. It is both a highly contagiousand a life-threatening disease [3]. Itsreproduction ratio (RR) is defined as the expected number of casesgenerated by a single infected individual within a susceptiblepopulation [5]. It varies between 2.4 and2.7 [6] These values are high compared toinfluenza ( $R R=1.3-1.8)$ [7].

Currently, a fight is being undertaken against the COVID-19pandemic. Adherence to control and prevention steps is paramountfor ensuring a complete success over COVID-19. Lessons were learnedfrom the 2003 SARS outbreak. These indicate that fear exists withinthe population awareness and attitude to infectious diseases. Thisfactor may hinder further efforts to prevent the virus spread.Therefore, it is 
crucial to understand COVID-19 public's awarenessat this critical stage to facilitate pandemic management $[8,9]$.

As members of the health care team, pharmacists play anessential role in patient care. This includes contributing to thedecision-making process within the multidisciplinary health careteam, taking responsibility for medication administration andassessment of patient care [10]. Moreover,together with physicians, pharmacists' knowledge, attitude andpractices are crucial to prevent and control the disease [11]. Health care teams include pharmacists and areresponsible for providing knowledge, delivering good qualitymanagement and protecting individuals from illness during epidemicprevalence period. Therefore, pharmacy students' education shouldinclude training in precautionary measures, effective treatment andfollow-up. This is critical together with their behavior in thesefields [12]. Normally, training indisaster medicine occupy a very small place in regular medicalcurricula worldwide [13]. Therefore, thepresent study was carried out to evaluate knowledge about COVID-19as an attempt to identify senior students' degree of awareness andits effects. Furthermore, this study objective aims to contributein developing a fit for purpose education program that createsawareness among future practitioners. To the best of the authors'knowledge, this is the first study directly exploring seniorpharmacy students' knowledge, attitudes and practice regarding thistopic.

\section{Subjects And Methods}

\section{Study design and population}

This is an institutional based cross sectional study conductedin Faculty of Pharmacy at the British University in Egypt duringthe period from April 28, 2020 to April 30, 2020. The targetedpopulation included students who had completed $\geq 85 \%$ of thecredit-hours required for graduation.

\section{Sample size}

The sample size was calculated by using the online sample sizecalculator RaoSoft ${ }^{\circledR}$. Based on an estimated population of 470 students in the final years (year four and five) and on theanticipated response of $50 \%$, the minimum required sample size was 204 participants with a confidence level of $95 \%$ and a $5 \%$ margin oferror.

\section{Study instrument}

A pre-validated questionnaire [14] wasmodified after a comprehensive literature search and based on themost recent available information from the World HealthOrganization, the Center for Disease Control and Prevention (USA)and the Egypt Ministry of Health . The initial draft was sent to agroup of experts, chosen according to their experience andexpertise in related fields, to appraise the questions in terms ofrelativity, simplicity and importance. Then, the questionnaire wassent by email, through Survey Monkey Software ${ }^{\circledR}$. A pilotstudy was conducted on 10 subjects, to test the questionnairevalidity. Following a 
group discussion, the questionnaire wascompleted. The data from the pilot study was removed from the finalanalysis.

The questionnaire included two sections: demographics, andknowledge, attitudes and practices questions (KAP). Demographicvariables included age, gender and place of current residence(Cairo, other governorates in Egypt). The first part of the KAPrepresented the knowledge investigation, consisting of 12 questions(Fig. 1): 4 questions were about COVID-19 clinical presentations(K1-K4), 3 asked about transmission routes (K5-K7), and thefollowing 5 questions quizzed on prevention and control (K8$\mathrm{K} 12$ ). These questions were answered on a true/false basis, including anadditional "I don't know" option. One point was assigned to acorrect response, while no points were given for anincorrect/unknown answer. The total score ranged from 0 to 12, witha higher score suggesting better COVID-19 awareness. In the pilotsample, the knowledge questionnaire Cronbach's alpha coefficientwas 0.73 , indicating reasonable internal consistency [15].

Attitudes towards COVID-19 were appraised with 2 questions(A1-A2, Fig. 2) that asked about the level of agreement on theCOVID-19 control implementations and the confidence perception forwinning the war against this coronavirus. The assessment of students practices was performed through 4 questions (P1P4, Fig.2), that investigated their actions towards going to a crowdedplace, wearing masks when going out in recent days, maintainingsocial distance between others and if they agree that patientsshould disclose their exposure to COVID-19. Finally, one lastquestion was added to inquire about the students' source ofCOVID-19 information.

\section{Ethical Considerations}

Before study start-up, permission was taken from the ethicscommittee of the Faculty of Pharmacy at the British University inEgypt. The participants were briefed about the study rationale andwere reassured about the confidentiality safeguards for theirpersonal information and responses. The answered survey submissionwas considered as consent for study participation. Respondents'participation was completely consensual, anonymous andvoluntary.

\section{Statistical analysis}

The completed questionnaires data were analyzed using theStatistical Package for Social Science, version 21.0 (SPSS 20.0,Chicago, IL). The significance level was set at a value of $p<0.05$ for all analyses. Initially, all information gathered throughthe questionnaire was coded into variables. In the pilot study, theCronbach's alpha coefficient test was used to measure internalconsistency. Data normality was tested using the Kolmogorov-Smirnovtest. Descriptive and inferential statistics, involving Chi-squaretest, MannWhitney $\mathrm{U}$ test, correlation and logistic regression,were used to analyze the results.

In the present study, the scoring system and categorization wereutilized to assess knowledge levels towards the COVID-19 pandemic.The questions determination was based on one point for everycorrect answer and zero points for false answers. By adding theresults of all the knowledge questions in the 
survey, theparticipants mean knowledge scores (KSs) were determined. KS rangedfrom 0 to 12, with the higher scores demonstrating an increasedlevel of pandemic COVID-19 knowledge. Knowledge level categorieswere defined by an $80 \%$ cut-off point as any score above $80 \%$ is goodand any score below $80 \%$ is poor [16].

\section{Results}

\section{Subjects' characteristics}

During the course of this study, a total of 248 participantscompleted the devised online survey questions. After excluding 10respondents who participated in the pilot study, the final sampleconsisted of 238 participant students. Among these, the average age(measured in years) was $22 \pm 1,166$ students (70\%) were females. When identifying the place of residence, 149 students $(63 \%)$ wereliving in greater Cairo while $89(37 \%)$ resided in othergovernorates (Table 1). With regards to the students' source ofinformation, results disclosed that the main source of informationwas social media $(70 \%)$ followed by published articles (48\%) andtelevision (48\%).

Table 1. Demographic profile of senior pharmacy students $(n=238)$

\begin{tabular}{lcc}
\hline \multicolumn{1}{c}{ Socio-demographiccharacteristics } & No. & (\%) \\
\hline Age (years) (mean \pm SD, range) & $22 \pm 1,19-26$ \\
Gender & \multicolumn{2}{c}{} \\
Male & 72 & 30 \\
Female & 166 & 70 \\
Place ofcurrent residence & & \\
GreaterCairo & 149 & 63 \\
Othergovernorates & 89 & 37 \\
& & \\
Sourcesof information & & \\
Physicians & 72 & 30 \\
Pharmacists & 81 & 34 \\
Friends & 45 & 19 \\
Socialmedia & 166 & 70 \\
Articles & 114 & 48 \\
TV & 114 & 48 \\
Knowledge score (mean \pm SD,range) & $10 \pm 1.2,4-12$ \\
Goodknowledge & 175 & 73.5 \\
Poorknowledge & 63 & 26.5 \\
\hline
\end{tabular}

\section{Characteristics of COVID-19 relatedknowledge}

In the present study, the main objective was to measure COVID-19related knowledge of pharmacy senior students. The mean score ofCOVID-19 related knowledge was $83 \%$ (10 \pm 1.2 , ranging from 4 to 12)(Table 1). In particular, $72.5 \%$ of the students possessed a goodknowledge level, while $23.5 \%$ displayed poor 
knowledge based on an80\% cut-off point [16]. The first 4 surveyquestions (K1-K4) measured students' knowledge towards COVID-19clinical presentations. The highest correct answer rate (98\%)related to the COVID-19 related knowledge items identified by 2questions; 'the main clinical symptoms of COVID-19 are fever,tiredness, and dry cough (True)' and 'older persons and personswith pre-existing medical conditions (such as high blood pressure,heart disease, lung disease, cancer or diabetes) appear to developserious illness with COVID-19 more often than others(True)'(Fig.1). However, the item with the lowest correctanswerrates was: 'coagulation dysfunction is one of the major causes fordeath in patients with severe COVID-19 (True)' (37\%) (Fig.1). Theanswer 'I don't know' was selected by $12 \%$ of students for thequestion 'COVID-19 may cause aches and pains, nasal congestion,runny nose, sore throat or diarrhea in some patients' (Fig.1). Thenthe following 3 questions (K5-K7) measured students' knowledgetowards the transmission routes. In this case, the percentage ofknowledgeable students is high (K.5: no transmission if fever isnot present (88\%); K6: COVID-19 can spread from person to personthrough small droplets (98\%); and K7: wear a mask only if you areill or looking after someone who may have COVID-19 (96\%). A similarresult was achieved with the next 5 questions (K8-K12), whichconcerned assessing knowledge about COVID-19 prevention and control(Fig.1). This study showed a significant relation between theknowledge score and published articles as source of information $(P<0.05)$.

\section{Characteristics of COVID-19 related attitude andpractice}

The students' attitude was measured with 2 questions. Thehighest positive result was attained by the followingCOVID-19-related attitude item: 'Are you confident that the healthcare team and scientists can win the fight against the COVID-19virus?' (87\% answered yes). However, the lowest positive attituderesult corresponded to the following: 'Do you agree that COVID-19will be successfully controlled?' (only $72 \%$ answered yes)(Fig.2).

The highest performance rate was attained by the followingCOVID-19-related practice item: 'In recent days, have you gone toany crowded place?' (87\% answered no). However, the item with thelowest performance rate was: 'In recent days, if you left yourhouse, have you worn a mask when leaving home?' (50.5\% gave anegative answer) (Fig.2). As expected, it was found that theCOVID-19 practice for going out in crowded place was significantlydifferent between males and females: females displayed a lowertendency to go out than males $(P<0.05)$. In addition, thepractice for keeping social distance between students wassignificantly different between males and females: femalesmaintained social distance more successfully than males $(P<0.05)$. It is worth mentioning that significant relations existedbetween the two practices and the students' source of information.In particular, the practice of wearing a mask when leaving home wasdirectly correlated with using television as source of information $(P<0.05)$. Furthermore, the practice of keeping social distanceof at least 2 meters from other people was directly associated withutilizing physicians' advice as source of information $(P<0.05)$.

Moreover, the correlation coefficient, existing between themajor knowledge, attitude and practice variables was analyzed. Aweak positive correlation was observed between attitude andpractice and this result 
appeared to be highly significant $(r=0.2 ; p<0.01)$. However, no correlation appeared to existbetween knowledge and attitudes or knowledge and practice (Table2).

Table 2. Correlation between knowledge, attitude andpractice

\begin{tabular}{lll}
\hline Variables & rho & P-value \\
\hline Knowledge \&cattitude & -0.058 & 0.37 \\
Knowledge \&practice & 0.006 & 0.891 \\
Attitude\& practice & 0.159 & $\mathbf{0 . 0 1 4 *}$ \\
\hline
\end{tabular}

Note: ${ }^{*} p<0.05$

Logistic regression analyses showed that students with a goodknowledge score are 2.2 times more optimistic and agreed thatCOVID-19 will be successfully controlled (95\% confidence interval[CI]: 1.034.72). Students who live in Cairo were 1.7 times morelikely to maintain social distance of at least 2 meters from otherpeople (95\% confidence interval [Cl]: 0.9-3.2)., and 1.7 times morelikely to agree that patients should disclose potential COVID-19exposure, than students who live in other governorates in Egypt(95\% confidence interval [CI]: 0.9-3.3). Moreover, female studentswere 3.6 times more likely to avoid going to any crowded place thanmale students (95\% confidence interval [Cl]: 1.5-8.6), and 2.3times more likely to keep their social distance of at least 2 meters from other people than male students $(95 \%$ confidenceinterval [Cl]: 1.2-4.4) (Table 3).

Table 3. Significantly associated factors towards COVID-19 logistic regression analysis of odds ratio (OR) for attitudes andpractices in relation to potential riskfactors.

\begin{tabular}{lllllcc}
\hline \multirow{2}{*}{ variable } & \multicolumn{2}{c}{ Attitude } & \multicolumn{4}{c}{ practice } \\
\cline { 2 - 6 } & \multicolumn{1}{c}{$\mathrm{A} 1$} & \multicolumn{1}{c}{$\mathrm{A} 2$} & $\mathrm{P} 1$ & \multicolumn{1}{c}{ P2 } & \multicolumn{1}{c}{ P4 } \\
\hline Knowledgecategory & $2.2^{*}(1.03-$ & $0.9(0.34-$ & $1.2(0.4-3.2)$ & $1.2(0.7-$ & $0.8(0.4-1.6)$ & $0.8(0.4-1.7)$ \\
& $4.72)$ & $2.04)$ & & $2.3)$ & & \\
Gender & $1.5(0.81-2.95)$ & $0.8(0.32-$ & $3.6^{*}(1.5-8.6)$ & $1.2(0.6-$ & $2.3^{*}(1.2-4.4)$ & $0.9(0.4-1.8)$ \\
& & $1.99)$ & & $2.2)$ & & \\
Age $^{\mathrm{a}}$ & $1.1(0.8-1.49)$ & $0.7(0.50-$ & $0.9(0.6-1.3)$ & $1.1(0.8-$ & $0.9(0.7-1.2)$ & $0.9(0.6-1.3)$ \\
& & $1.17)$ & & $1.4)$ & & \\
residence & $1.2(0.66-2.24)$ & $1.3(0.59-$ & $0.8(0.3-$ & $0.9(0.5-$ & $1.7^{*}(0.9-3.2)$ & $1.7^{*}(0.9-3.3)$ \\
& & $3.00)$ & $2.03)$ & $1.5)$ & & \\
\hline
\end{tabular}

Note: $* p<0.05$

a: Scoredas continuous variable

\section{Discussion}

The coronavirus disease 2019 (COVID-19) is an emergingcontagious respiratory disease caused by a novel coronavirus. Itwas first detected in December 2019 in Wuhan, China [17]. Emerging infectious diseases like COVID-19can occur anywhere in the world. By being part of the health careteam, pharmacists can be exposed to the risk of infection [18]. Here, we present the results of aquestionnaire 
study about the knowledge, attitudes and practices ofEgyptian senior pharmacy students towards the COVD-19 disease.

In the present study, one of the most significant findings wasthat the highest main source of COVID-19 information among seniorstudents was social media, television and published articles. Theresults strongly support similar findings in which the main sourceof Middle East respiratory Syndrome (MERS) information was reportedto be the internet and social media [19]. This clearly indicates that senior pharmacy students are relyingconsistently on the internet, social media and online informationas the principal ways to obtain information, compared with friendsand other resources. The Egyptian Ministry of Health and Populationand the World Health Organization (WHO) have provided clusters withCOVID-19 information through their websites and are recommendingeveryone to be aware of updates relating to knowledge aboutCOVID-19 [3, 4].Similarly, a previous study reported that internet was the mainsource of information about MERS-CoV [20].Therefore, it is feasible to suggest that researches shouldurgently find ways to utilize the Internet to promote health,especially in emerging infectious diseases and pandemics. Atpresent, the quality of the information available on the Internetis insufficient and needs to be revised. Furthermore, a very smallpercentage of participants reported that healthcare professionals,either physicians or pharmacists, were their primary source ofinformation. This scenario illustrates the lack of healthcare teamengagement in increasing the public awareness regarding differentaspects of COVID-19.

The present study showed a significant relation existing betweenthe knowledge score and published articles as source of information $(\mathrm{P}<0.05)$. That may be due to the role played by the WHO andthe Egyptian Ministry of Health and Population in providing clusterwith COVID-19 information through their websites. Therefore, theseorganizations recommend everyone to be aware of updates aboutCOVID-19.

As mentioned earlier, 238 senior pharmacy students participatedin the present study. The overall mean knowledge scored amongstudents was $83 \%$ (10 \pm 1.2$)$. Most of the students possessed a goodCOVID-19 knowledge level (72.5\% of the students), possibly owing tothe fact that the Egyptian Ministry of Health and Population (MOHP)and the World Health Organization (WHO) are providing a significant amount of COVID-19 information through theirwebsites [3, 4].The present study results showed that $98 \%$ of participants wereknowledgeable about the main clinical symptoms of COVID-19. Inaddition, the same percentage of students knew that older personsand persons with pre-existing medical conditions were more liableto develop serious illness with COVID-19 than others. Thesefindings confirm observations from previous studies, which reportedthat the majority of participants believed that the disease is moredangerous for the elderly and for those suffering from chronicdiseases [21, 22].

The students were least knowledgeable towards the question ofcoagulation dysfunction being one of the major death causes inpatients with severe COVID-19. Suitable remedial actions should betaken since vascular, venous thromboembolism and arterialthrombosis risks have been documented in severe and critically illCOVID-19 patients [23, 24]. A perceived lack of information regardingsome of the COVID-19 clinical presentation or preventive measureshighlights the requirement for the inclusion of more training,seminars in their courses. This raises concerns regarding theability of newly-graduated 
pharmacists to deal with the COVID-19pandemic disease, or any other potential similar epidemic events.Also, the students were least knowledgeable about when to wearmasks. Masks and sanitizing products use has evolved since thebeginning of the coronavirus pandemic, resulting in their rapiddepletion. Lack of appropriate security measures represents a majorconcern for health workers. This is a cause of concern in a highlypopulated country such as Egypt, where the public may experienceanxiety and even panic feelings, because basic protection measuresare unavailable [25].

Knowledge is a prerequisite for establishing positive attitudesand promoting positive behaviors. Therefore, it makes sense toinvest in individuals' cognition towards the infection. Regardingthe senior students' attitude towards COVID-19, in the presentstudy $72 \%$ of them agreed that COVID-19 will be successfullycontrolled and $87 \%$ were confident that health care teams andscientists can win the fight against the coronavirus. Interestingly, it was found that a greater students' knowledgerelates to more confidence in COVID-19 becoming successfullycontrolled ( $O R=2.2,95 \%$ confidence interval [CI]: $1.03-$ 4.72).

Correlation between the students' attitude and practiceindicates that their positive attitude is affecting their actiontowards COVID-19. This present study results showed that $87 \%$ ofparticipants did not go to any crowded place, $76 \%$ of the studentsagreed that patients should disclose their exposure to COVID-19 and $73 \%$ of the students kept the social distance of at least 2 metersfrom other people. However, the students showed bad practice whenusing masks as a protective measure (approximately $50 \%$ ). That wasdirectly related to their lower level of knowledge towards theimportance of wearing masks $(P<0.05)$. That is supported byfindings from a previous study, which reported that only about $35 \%$ of the participants were willing to wear face masks [21].

Interestingly, it was reported that females preferred not to goto any crowded place more than male students ( $\mathrm{OR}=3.6,95 \%$ confidence interval $[\mathrm{Cl}]: 1.5-8.6)$. In addition, females preferredto keep the social distance more than male students ( $O R=2.3,95 \%$ confidence interval [Cl]: 1.2- 4.4). Moreover, students who live inother governorates kept social distance and agreed that patientsshould disclose their exposure to COVID-19 rather than the studentswho live in the capital (OR $=1.7,95 \%$ confidence interval [CI]:0.9-3.2).

It is noteworthy that a significant association existed betweenthe practice of wearing masks when leaving home and usingtelevision as source of information $(P<0.05)$. Likewise, anassociation existed between the practice of keeping the socialdistance at least 2 meters from other people and utilizingphysicians as a source of information $(P<0.05)$. Thisencourages the public to avoid public meetings, including sports,ceremonies, meetings and school classes, in order to prevent aglobal transmission of coronavirus infection [26]. However, many people ignore the importance ofmaintaining social distance because of attitudinal issues.

\section{Conclusion And Recommendations}

It can be concluded that senior pharmacy students are generallyknowledgeable about COVID-19. They lack knowledge about some of theclinical presentation of severe COVID-19 infection such ashyper- 
coagulation. They also lack knowledge about the indication ofwearing face masks. The present study constitutes the first attemptto examine knowledge and perceptions of future pharmacists in Egypton pandemic diseases. Finally, the analysis of senior pharmacystudents' knowledge and the factors affecting their attitudes andpractices towards COVID-19 could provide a reference for preventingfurther spread of this disease.

It is recommended that strategies and education programs shouldbe implemented to reduce the risk of infection among futurepharmacists. Senior pharmacy students should acquire increasedawareness regarding the seriousness and consequences of a COVID-19infection.

\section{Limitations of the Study}

Some of the results of this study were compared with research onother new emerging infectious diseases similar to coronavirus,because no analyses have been conducted concerning pharmacystudents or students in general.

\section{Declarations}

\section{Compliance with Ethical Standards}

Conflict of interest: The authors declare thatthey do not have conflict of interests.

\section{Acknowledgments}

The researchers acknowledge our senior pharmacy students whotook part in this study.

\section{References}

1. Fauci, A.S. and H.C. Lane, Covid-19 - Navigating theUncharted. 2020. 382(13): p. 1268-1269 DOI:10.1056/NEJMe2002387.

2. Carsetti, R., M.M. Rosado, S. Donnanno, et al., The loss oflgM memory B cells correlates with clinical disease in commonvariable immunodeficiency. J Allergy Clin Immunol, 2005.115(2): p. 412-7 DOI:10.1016/j.jaci.2004.10.048.

3. World Health Organization. Coronavirus Disease 2019(COVID-19) Situation Report-117.situationreports/20200311-sitrep-51-covid-19.pdf?sfvrsn=1ba62e57_102020 May 16 2020]; Available from: https://www.who.int/emergencies/diseases/novel-coronavirus-2019

4. Ministry of Health-Egypt. COVID-19 Overview. 2020 May16 2020]; Available from: https://www.care.gov.eg/EgyptCare/Index.aspx.

5. Fraser, C., C.A. Donnelly, S. Cauchemez, et al., Pandemicpotential of a strain of influenza A (H1N1): early findings.Science, 2009. 324(5934): p. 1557-61 DOl:10.1126/science.1176062.

6. Liu, Y., A.A. Gayle, A. Wilder-Smith, and J. Rocklov, Thereproductive number of COVID-19 is higher compared to SARScoronavirus. J Travel Med, 2020. 27(2) DOI:10.1093/jtm/taaa021. 
7. Biggerstaff, M., S. Cauchemez, C. Reed, M. Gambhir, and L.Finelli, Estimates of the reproduction number for seasonal,pandemic, and zoonotic influenza: a systematic review of theliterature. BMC Infectious Diseases, 2014.14(1): p. 480 DOI: 10.1186/1471-2334-14-480.

8. Ajilore, K., I. Atakiti, and K. Onyenankeya, Collegestudents' knowledge, attitudes and adherence to public serviceannouncements on Ebola in Nigeria: Suggestions for improving futureEbola prevention education programmes. Health Education Journal, 2017. 76(6): p. 648-660 DOI:10.1177/0017896917710969.

9. Tachfouti, N., K. Slama, M. Berraho, and C. Nejjari, Theimpact of knowledge and attitudes on adherence to tuberculosistreatment: a case-control study in a Moroccan region. The PanAfrican medical journal, 2012. 12: p. 52-52.

10. Babiker, A., M. El Husseini, A. Al Nemri, et al., Healthcare professional development: Working as a team to improve patientcare. Sudanese journal of paediatrics, 2014.14(2): p. 9-16.

11. Askarian, M., M. Danaei, and V. Vakili, Knowledge,Attitudes, and Practices Regarding Pandemic H1N1 Influenza AmongMedical and Dental Residents and Fellowships in Shiraz, Iran.Int J Prev Med, 2013. 4(4): p. 396-403.

12. Khowaja, Z.A., M.I. Soomro, A.K. Pirzada, M.A. Yoosuf, and V.Kumar, Awareness of the Pandemic H1N1 Influenza global outbreak2009 among medical students in Karachi, Pakistan. J Infect DevCtries, 2011. 5(3): p. 151-5 D0I:10.3855/jidc.1247.

13. Scott, L.A., D.S. Carson, and I.B. Greenwell, Disaster 101:a novel approach to disaster medicine training for healthprofessionals. J Emerg Med, 2010. 39(2): p.220-6 DOI: 10.1016/j.jemermed.2009.08.064.

14. Zhong, B.-L., W. Luo, H.-M. Li, et al., Knowledge,attitudes, and practices towards COVID-19 among Chinese residentsduring the rapid rise period of the COVID-19 outbreak: a quickonline cross-sectional survey. International journal ofbiological sciences, 2020. 16(10): p. 1745-1752DOI: $10.7150 /$ ijbs.45221.

15. Taber, K.S., The Use of Cronbach's Alpha When Developingand Reporting Research Instruments in Science Education.Research in Science Education, 2018. 48(6): p.1273-1296 DOI: 10.1007/s11165016-9602-2.

16. Dhimal, M., K.K. Aryal, M.L. Dhimal, et al., Knowledge, attitude and practice regarding dengue fever among the healthypopulation of highland and lowland communities in centralNepal. PLoS One, 2014. 9(7): p. e102028 DOl:10.1371/journal.pone.0102028.

17. Chen, N., M. Zhou, X. Dong, et al., Epidemiological andclinical characteristics of 99 cases of 2019 novel coronaviruspneumonia in Wuhan, China: a descriptive study. The Lancet,2020. 395(10223): p. 507-513 DOI:10.1016/S0140-6736(20)30211-7.

18. Hedima, E.W., M.S. Adeyemi, and N.Y. Ikunaiye, CommunityPharmacists: On the frontline of health service against COVID-19 inLMICs. Research in social \& administrative pharmacy : RSAP,2020: $p$. S1551-7411(20)30385-5 DOI:10.1016/j.sapharm.2020.04.013. 
19. Khan, M.U., S. Shah, A. Ahmad, and O. Fatokun, Knowledgeand attitude of healthcare workers about Middle East RespiratorySyndrome in multispecialty hospitals of Qassim, Saudi Arabia.BMC Public Health, 2014. 14: p. 1281 DOI:10.1186/1471-2458-14-1281.

20. Hoda, J., Identification of information types and sourcesby the public for promoting awareness of Middle East respiratorysyndrome coronavirus in Saudi Arabia. Health Educ Res, 2016.31(1): p. 12-23 DOI: 10.1093/her/cyv061.

21. Abdelhafiz, A.S., Z. Mohammed, M.E. Ibrahim, et al.,Knowledge, Perceptions, and Attitude of Egyptians Towards theNovel Coronavirus Disease (COVID-19). J Community Health, 2020DOI: 10.1007/s10900-020-00827-7.

22. Li, L.Q. and T. Huang, COVID-19 patients' clinicalcharacteristics, discharge rate, and fatality rate ofmeta-analysis. 2020 DOI: 10.1002/jmv.25757.

23. Tang, N., H. Bai, X. Chen, J. Gong, D. Li, and Z. Sun,Anticoagulant treatment is associated with decreased mortalityin severe coronavirus disease 2019 patients with coagulopathy.J Thromb Haemost, 2020 DOI: 10.1111/jth.14817.

24. Guan, W.J., Z.Y. Ni, Y. Hu, et al., ClinicalCharacteristics of Coronavirus Disease 2019 in China. N Engl JMed, 2020 DOI: 10.1056/NEJMoa2002032.

25. Feng, S., C. Shen, N. Xia, W. Song, M. Fan, and B.J. Cowling,Rational use of face masks in the COVID19 pandemic.Lancet Respir Med, 2020. 8(5): p. 434-436 DOI:10.1016/s2213-2600(20)30134-x.

26. McCloskey, B., A. Zumla, G. Ippolito, et al., Massgathering events and reducing further global spread of COVID-19: apolitical and public health dilemma. The Lancet, 2020.395(10230): p. 1096-1099 DOI:10.1016/S0140-6736(20)30681-4.

\section{Figures}




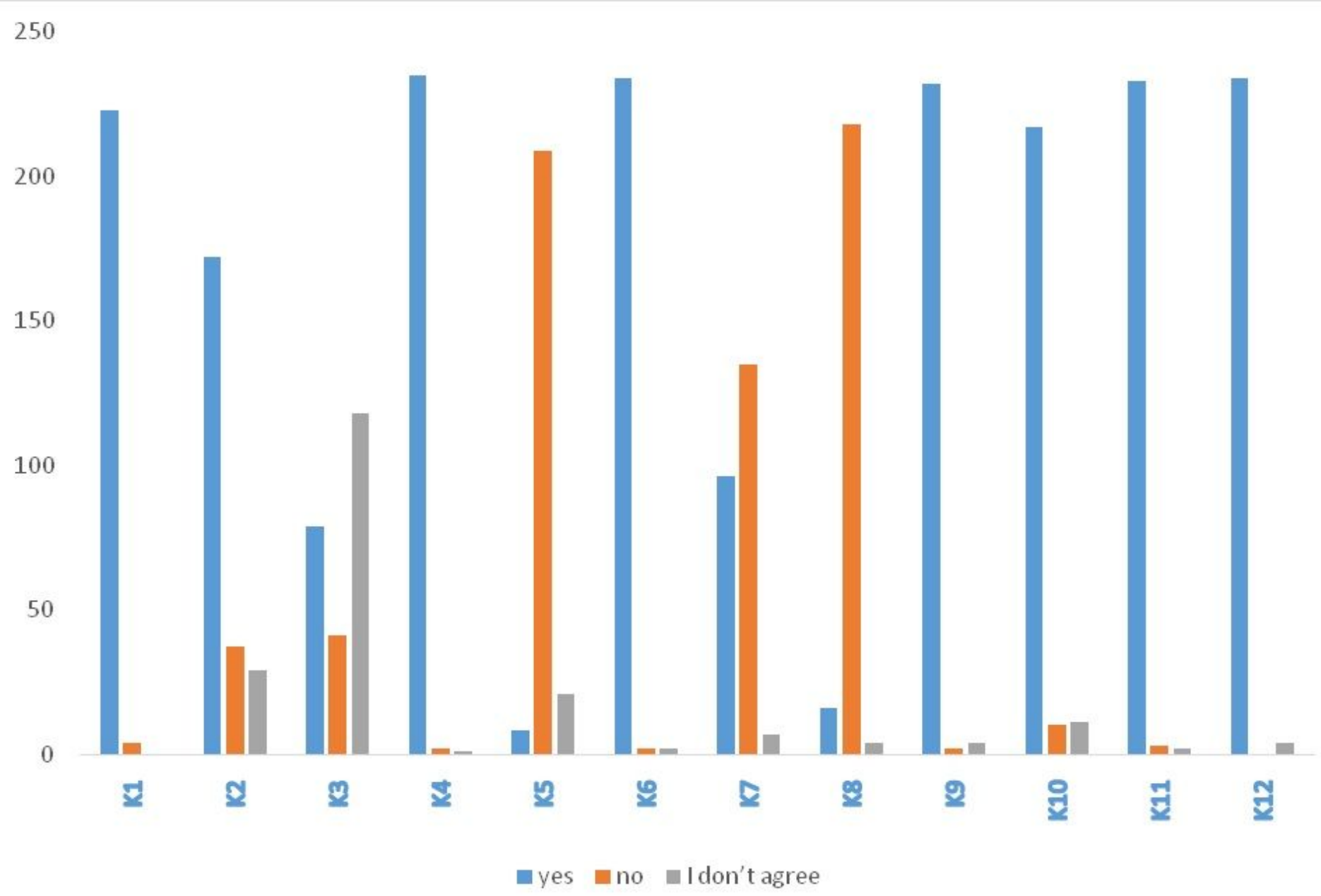

Figure 1

Knowledge of students towards COVID-19 K1. The main clinical symptoms of COVID-19 are fever, tiredness, and dry cough, K2 Some patients infected with the COVID-19 virus may suffer from aches and pains, nasal congestion, runny nose, sore throat or diarrhea, K3. Coagulation dysfunction is one of the major causes for death in patients with severe COVID-19, K4. Older persons and persons with pre-existing medical conditions (such as high blood pressure, heart disease, lung disease, cancer or diabetes) appear to develop serious illness with COVID-19 more often than others, K.5 People with COVID-19 will not transmit the virus to others when fever is not present, K6. COVID-19 can spread from person to person through small droplets from the nose or mouth which are spread when a person with COVID-19 coughs or exhales, K7. Only wear a mask if you are ill with COVID-19 symptoms or looking after someone who may have COVID-19, K8. It is not necessary for children and young adults to take measures to prevent the infection by the COVID-19 virus, K9. To prevent the infection by COVID-19, individuals should avoid going to crowded places such as public transportation, K10. COVID-19 is caused by a virus, so antibiotics do not work. Antibiotics should not be used as a means of prevention or treatment of COVID-19. They should only be used as directed by a physician to treat a bacterial infection, K11. Isolating and treating people 
with COVID-19 infections are effective means of minimizing viral spread, K12. People who have contact with someone who has COVID-19 infection should be isolated in a proper place immediately. The observation period is usually 14 days.

250

200

150

100

50

0
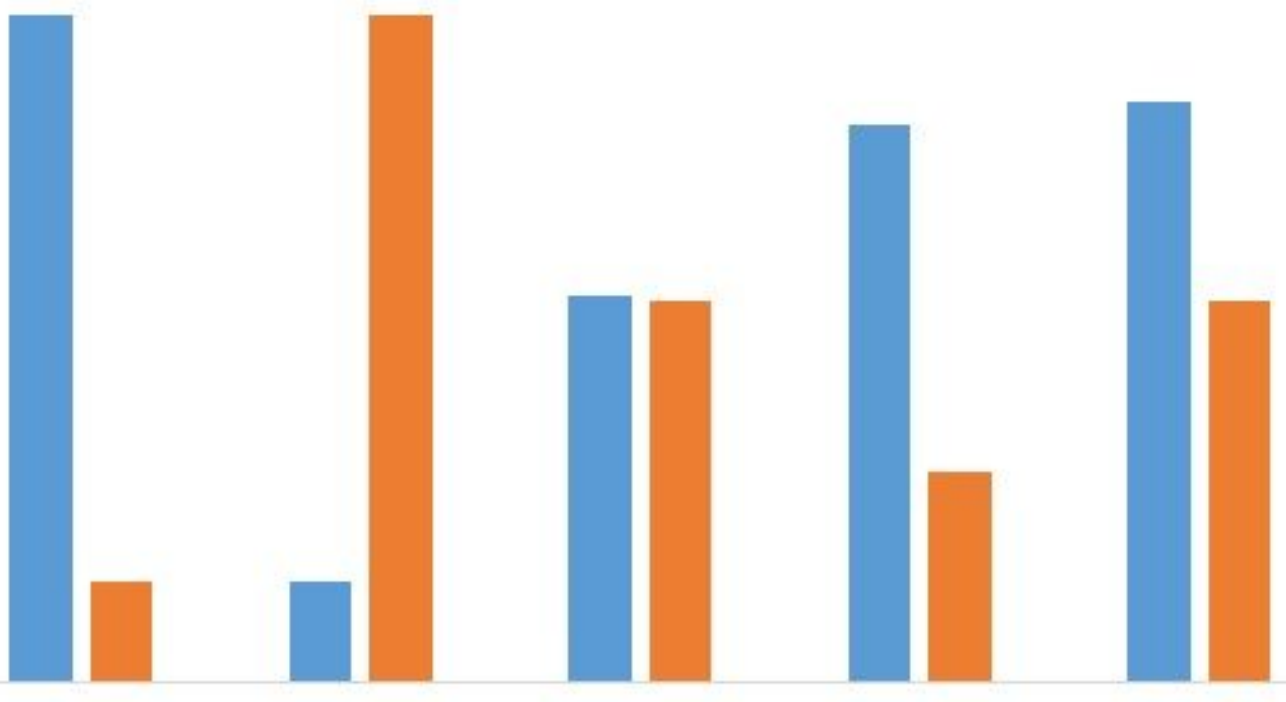

A1

A2

P1

P2

P3

P4

myes no

\section{Figure 2}

Attitudes \& practice of students towards COVID-19 A1. Do you agree that COVID-19 will be successfully controlled? A2. Are you confident that the health care team and scientists can win the fight against the COVID-19 virus? P1. In recent days, have you gone to any crowded place? P2. In recent days, if you left your house, have you worn a mask when leaving home? P3. In recent days, did you keep your social distance at least 2 meters from other people? P4. Do you agree that patients should disclose their exposure to COVID-19? 